\title{
WHERE DO WE GO
}

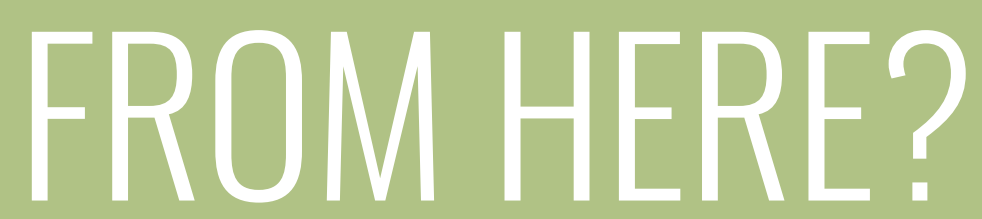

A Reflection on We Can't

Go Back: A Video Interview

Series Focused on Anti-

Racism in Arts \& Cultural

Education

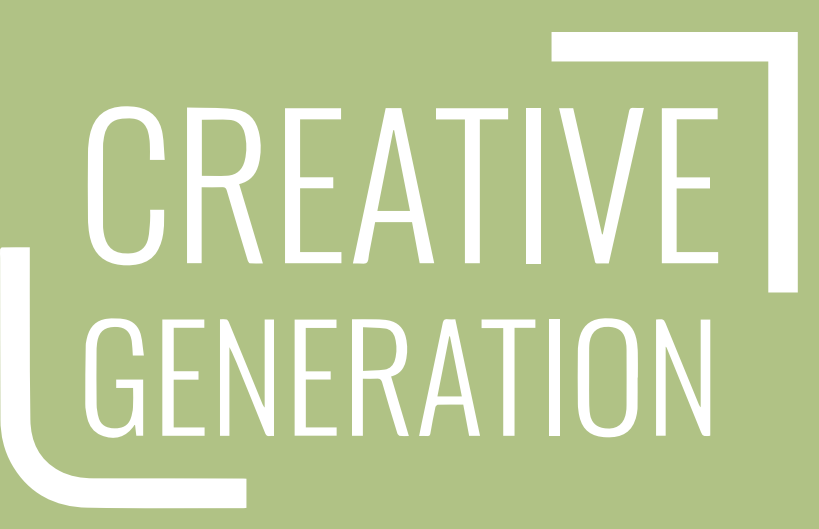




\section{ТEAGนNOM \\ ARTISTRY \\ . \\ Countney \&. Boddie}

The Teaching Artistry with Courtney J. Boddie podcast blends creative and educational practice in service of community building, social justice, and inspiring joy. Courtney J. Boddie, host and creator, chats with artists, teaching artists and arts educators who are driving professional teaching artistry forward. Courtney and her guests discuss personal journeys, celebrate triumphs and challenges, and advocate fiercely for the arts in all communities.

www.teachingartistry.org

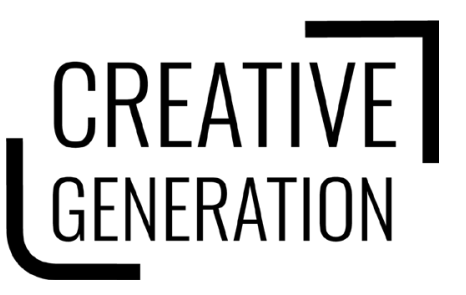

Contributing to the development of thriving communities and a more just world, Creative Generation works to inspire, connect, and amplify the work of young creatives who catalyze social change and those who are committed to cultivating their creativity. Founded in 2019, Creative Generation operates four signature programs: The Campaign for a Creative Generation, the Institute for Creative Social Transformation, The Academy for Creative Leadership, and the Incubator for Creative Impact. www.Creative-Generation.org

This refection was authored by André Solomon.

Suggested citation:

Solomon, A. (2021) Where Do We Go From Here? A Reflection on We Can't Go Back: A Video Interview Series Focused on Anti-Racism in Arts \& Cultural Education. Creative Generation, Washington, D.C. DOI: 10.51163/CREATIVE-GEN003

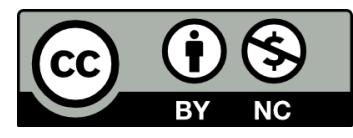

This work is licensed under the Creative Commons Attribution-NonCommercial 4.0 International License. To view a copy of this license, visit http://creativecommons.org/licenses/by-nc/4.0/ or send a letter to Creative Commons, PO Box 1866, Mountain View, CA 94042, USA. 


\section{Table of Contents}

Foreword 4

Introduction 6

Section 1: Power, the Root Problem of Racism 8

Re-Distributing Power 8

Avoid Dominating Resources 9

Eliminating Performative Allyship 9

Becoming an Accomplice 10

Section 2: BIPOC Seeking Reparations, Awarded in Full 12

Listening First 12

Adopting an Abolitionist Mindset 13

Creating Pathways to Reparations 13

Section 3: Decolonizing the Arts and Cultural Education Field 15

Staying Attentive 15

Creating Braver and Liberated Space 16

Honoring Expertise 16

\section{A Call to Action 18}

Project Archive 19

Recommended Resources 22 


\section{FOREWORD}

For me, André Solomon, serving as the project manager, video producer, and documentarion of the We Can't Go Back project was an opportunity to learn and absorb Blackness, as I continually pledge to elevate BIPOC voices in and outside of the arts. In an introductory blog post for the series, I wrote about my own experience:

On June 29th of 1999, his father (Black) was shot before his eyes in a hate crime that defaulted whiteness upon him, his mother's racial identity. With minimal efforts from his white family to learn about his culture, he had no Black mentors or allies to teach him. "This is why representation is crucial to youth development," says André. Without diverse resources to connect to, the mind is easily moldable to believe whatever it experiences. Because of this experience he was committed - committed to fighting for causes with the intention of protecting anyone from experiencing his confusing timeline, where being Black was not supported. He believes we must work together to distribute power among races and hold each other accountable because, whether it is an orchestra unwilling to hire BIPOC staff or a man receiving a reduced charge for murder, we cannot live in a world that tolerates injustice.

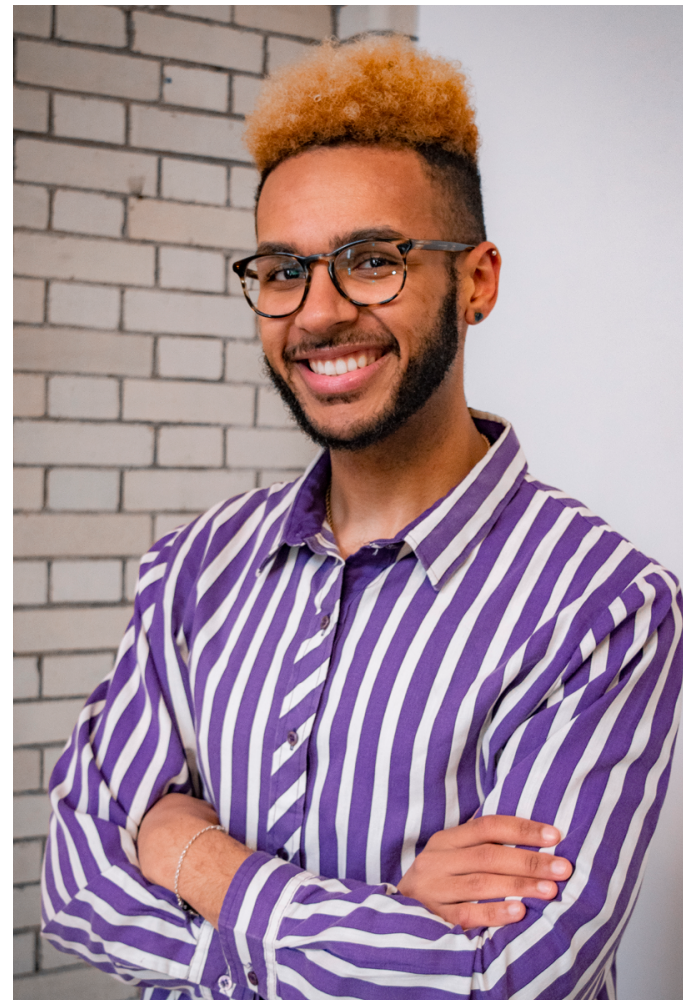

The year 2020 forcibly exposed civil unrest across the United States in response to the pandemic of racism and White Supremacy. Communities are now experiencing a new kind of revolution where the goal of a complete arts and cultural education is intertwined with the continued struggle for freedom from oppression and fight for equality.

Therefore, this project - and the team working on it - desired to elevate the knowledge of leaders from communities engaged in conversations about the intersection of race, power, culture, and learning.

Our work had urgency: in the wake of the pause resulting from the COVID-19 pandemic, communities cannot return to "normal," but rather revise their visions of a new future. 


\section{FOREWORD}

For me, Courtney J. Boddie, creator and host of the Teaching Artistry podcast, the podcast has always been a reflection of my own journey and how I learn from those in the arts and culture community. Previously. I have dedicated my work to equity and belonging. But in June 2020, all my work felt like it was not radical enough - I felt that I had been playing things safe - making incremental changes, navigating the [white-led] systems and spaces - rather than demanding the spaces change.

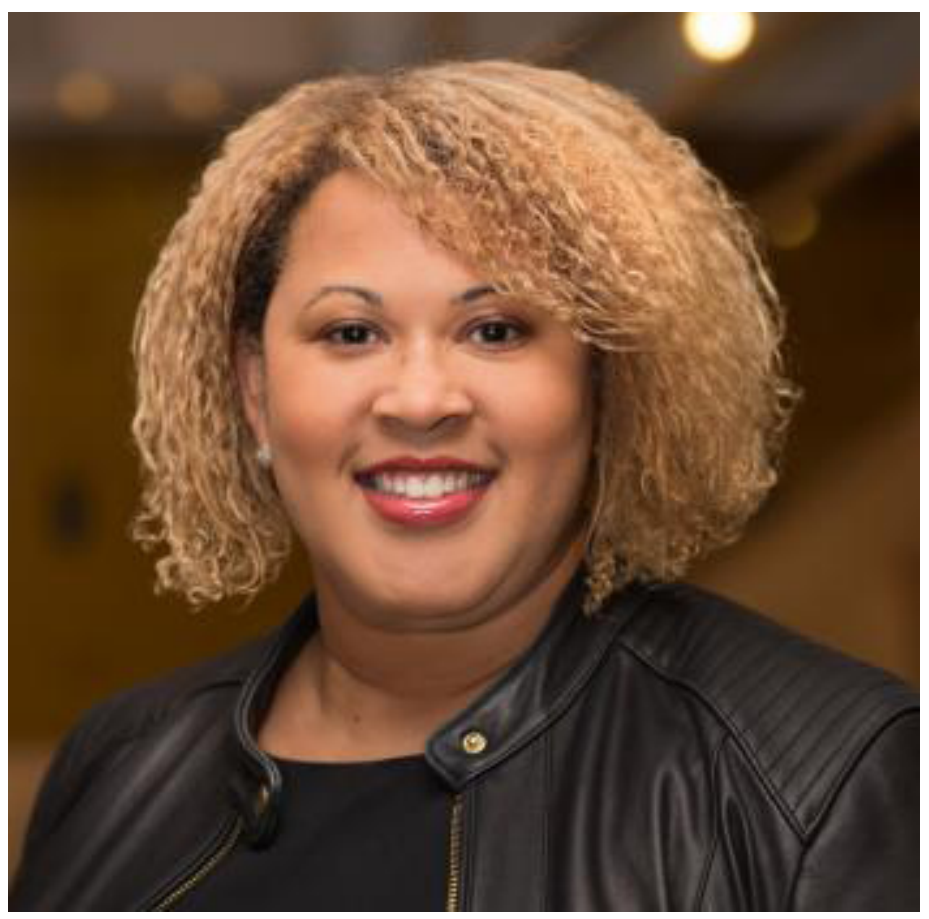

I was in a place of internal interrogation and examining - a place of inquiry that came from the emotional space. I looked to my ancestors; most recent of whom is my mother. At this inflection point, however, my immediate thoughts were of my father integrating his college campus in the deep south during the early 1960's. There is a history, led by people, which we can learn from. These voices, though, must be documented; hence why we are producing this document.

As a bridge from ending the video series \#KeepMakingArt to the release of We Can't Go Back, I share his experience in relation to my self-examination in relation to antiracist ideas and practices. These ideas and practices are, too, led by others - often my own contemporaries - which have influenced my own perspective as a practitioner. The chance to share their genius, their struggles, their practices in arts and arts education is momentous. This video series, and resulting reflection, are tools that inform us and document the changes occuring around us during an important period in our collective history - we can't go back. 


\section{INTRODUCTION}

The journey's been real y'all.

From August to December 2020, the Teaching Artistry with Courtney J. Boddie podcast collaborated with twenty-two inspiring artists, educators, and community activists - twentyone of whom are Black, Indigenous, and People of Color (BIPOC) - through the We Can't Go Back project to follow their journeys as they raised their consciousness in anti-racist, liberatory, and intersectional feminist practices through the arts.

The end result of the We Can't Go Back project, is an archive of the video interview series and this cumulative reflection, which highlights the many practices, strategies, and fundamental shifts in arts and cultural work - both pedagogical and institutional - shared throughout the project to both document and spur the reimagination of a future we move toward.

In total, twenty videos and blog posts aggregate leadership strategies, educational tools, and an archive of the stories of BIPOC professionals whose work took action inspired by the murders of George Floyd, Breonna Taylor and other countless victims at the hands of police to further community understanding, counteract White Supremacy, and disassemble anti-Blackness in cultural and educational systems.

We wish to express our greatest gratitude for the many guests of the podcast for the We Cant Go Back series, including Chesney Snow, Michael J. Bobbitt, Khalia Davis, Adia Tamar Whitaker, Quanice G. Floyd, Toya Lillard, C. Brian Williams, Ashley Herring, Robyn Walker Murphy, Durell Cooper, Peter J. Kuo, Dr. Daphne Sicre, Takiema Bunche Smith, Jody Drezner Alperin, Cardozie Jones, Alaina Newell, Dexter J. Singleton, Carin Ford, Lisa Dawn Cave, Christina Eskridge, ChelseaDee Harrison, and Idris Goodwin

In this reflection, documentarians have identified common trends among the public interview archives, and presented them in three sections which encapsulate the major concepts and collect relevant tools and resources to help enable readers to more deeply engage with the complex topics shared throughout the series. These include:

- Power, the Root Problem of Racism

- BIPOC Seeking Reparations, Awarded in Full

- Decolonizing the Arts and Cultural Education Field

Our hope is that each reader can deepen their knowledge and find multiple access points to their learning about the complex topics throughout.

In 2020, similar movements served as the catalyst for change due to the multitude of extreme circumstances revealing the deep-rooted nature of supremacist systems pervading American culture. The COVID-19 pandemic exposed America's racial pandemic related to access to resources aimed at health and wellbeing. The political divide underscored the divisions of enfranchisement engrained in the voting rights movement. The unstable economy amplified the impacts of the former. However, in the summer months of 2020, organized groups of 
BIPOC held decision-makers accountable through organized movements, civil unrest, and political organizing.

The arts education field served as a microcosm of the scenario being played out in American society. Throughout this project, however, we heard repeatedly that change must derive from an abolitionist framework. Our field must not cancel individuals, but rather use the current willingness to cultivate excellence within the sector.

We continued to learn this through the very processes of this project; and we thank those who invested their time and energy in our continued learning.

From our observations, review, and analysis of the perspectives publicly shared on the Teaching Artistry podcast of anti-racism practices (and the circumstances in which they occurred) within the arts and education sectors, we have drawn together a number of ideas and discussion points. We do not view ourselves as experts, but rather as observers, dedicated thinkers, and question-askers. We hope that readers pause and reflect on their role. Are you aiding the movement for lasting change? Have you unknowingly supported a supremacist system? We all have a responsibility to learn. We invite you to use this reflection as a tool towards achieving a racially just world - that is the ultimate goal.

Throughout this document, we have compiled a few self-reflective questions to guide your exploration in each section. As a reader, think about:

- How does power influence my actions?

- What is the best way to meaningfully uplift the BIPOC community?

- What actions can I take?

- What can I do with this privilege to activelysupport those who have been oppressed in the effort to construct a racially-just world?

We recognize that the world is ever-changing and since the completion of this project in December 2020, numerous traumatic events have occurred which may have influenced the findings of this report. We have chosen to produce this document unaltered as an archive of the We Can't Go Back project and the learnings, ideas, and resources identified throughout. 


\section{SECTION 1: POWER, THE ROOT PROBLEM OF RACISM}

May 25, 2020, the day marked by the murder of George Floyd, was a moment to recognize that white supremacy reigns supreme in America. Collectively, American society reckoned with (yet) another example of racism in the country. At it's root, though, is the disparity of power and its inequity which impacts human lives. As a practitioner, we encourage you to think: How does power influence my

\section{actions?}

In this section, we will share our reflections on how racialized power influences the systems supporting arts and cultural education, related to the following big ideas:

- Re-Distributing Power

- Avoid Dominating Resources

- Eliminating Performative Allyship

- Becoming an Accomplice

In a country becoming "minority white" by 2045, American society must acknowledge the changing makeup of our communities and the current reconciliation with systems built on white supremacy Whether curricular, philanthropic, or institutional, the systems which have embraced a white domination of power must adapt to reflect the American populace. With racism's extended historical timeline, moments occurred to challenge this status quo (i.e. the Stono Rebellion 1739, Civil War, the Civil Rights Movement, and Black Lives Matter) and more often than not, those movements were suppressed in an effort to maintain power by the white majority. This history shows that in times of systemic reconciliation, those same systems being reformed provide loopholes which may be exploited to secure power for the majority and continue the oppression of the minority. We must let history be our teacher and work to ensure this pattern does not repeat itself.

Common throughout all interviews was the conception that the root of racism lies in power. That power is supported by the centuries-strong domination of resources by white people resulting from the systems created to reinforce cultures of white supremacist ideals. These ideals are exemplified in power hoarding and performative allyship.

\section{Re-Distributing Power}

Michael J. Bobbitt said, "racism will never end unless white individuals comply with distributing power amongst everyone." What fuels the hoarding of power in 2020? The Darwinian concept of "survival of the fittest" and the American institution of capitalism combine to generate individualist approaches to success devoid of collective benefit; many refer to this as the pursuit of the American Dream. These ideas have been employed by generations of white people to justify their actions to enshrine individual advancement and avoid distribution of power through the collection of excess resources. When combined with the racial history of the United States, these processes have resulted in the crafting of systems of oppression, codifying racism, and resulting in gigantic gulfs of power.

To realize a vision of power redistribution and thus start the move towards power sharing, white people must act as accomplices in anti-racism. Idris Goodwin points out that "...it is going to take a lot of white individuals to stop racism because it was designed to help them out." This form of anti-racism 
is more complex than modifying language or removing restrictive policies: it is difficult because it is about redefining what is actually needed for success, reducing individual excess, and embracing the unknown. In a world where people often denounce what is foreign to them, this process must be about embracing foreign-ness. Instead of "I can't," it must be "What can I do?"

\section{Avoid Dominating Resources}

This shift is not just individual. Predominately white institutions (PWIs) must avoid dominating resources as well. In an effort to mitigate risk and continue their work, PWIs engage people (whether as board members, organizational leaders, spokespeople, and the like) with significant positional power supplied by the systems of oppression previously discussed. Problematic policies and persistent lack of accountability create circumstances enabling power hoarding by individuals within their ranks and thus for the institution. This results in PWIs dominating resources within their community.

As an example, let's examine the response to government stimulus funds during the COVID-19 pandemic. The year 2020 amplified the myriad risks often survived by the arts and cultural sector: market fragility, dependence on un-diversified income, insufficient support of staff, etc. With their ample infrastructures, PWIs moved to capture government resources while making inequitable cuts to staffing (thus continuing the persistent sector-wide pre-pandemic problem). Toya Lillard observed: "Your favorite nonprofit received a Paycheck Protection Program (PPP) loan in the millions and laid off half its staff" as an example of this behavior.

Realizing their position of power with sufficient resources at the start of the pandemic, what other course of action could the PWI take? One may not think of counteracting this behavior as antiracism, however, imagine the world where those stimulus checks were used to continue employment for those previously disenfranchised. Or, better yet, imagine if those well-financed PWIs withdrew their PPP applications and supported smaller, BIPOC-run organizations with their application to receive funds.

\section{Eliminating Performative Allyship}

During this time, many individuals and organizations committed themselves to producing work that amplified marginalized voices, recognizing the power of this work to promote empathy and generate crucial conversations. Ideally, they hoped, these efforts would have a positive effect on dismantling oppressive systems. This type of investment is known as performative allyship. It outwardly satisfies the public eye, while inwardly does not change any ingrained racism.

Individuals and PWIs must eliminate performative allyship and instead engage in co-conspiring to disassemble the systems of oppression within their work and organizations. For instance, take these two common examples:

- The board of a PWI has auxiliary committees committed to Diversity/Equity/Inclusion/Accessibility (DEIA) but they hold no power to amend racist policies or question leadership decisions. How can we, as individuals and organizations, eliminate the performative nature of these committees and more actively share power to co-conspire for meaningful internal change?

- As justice-focused arts practices document powerful results with communities, a PWI engages with community philanthropists to fund this type of work through their own institution, without any real alignment to their mission. How can the individuals or institutions use their positional power to align these funds with the practitioners or organizations already doing this work in their community? 


\section{Becoming an Accomplice}

Anti-racist work requires white-identifying people to participate in the process - not just as an ally, but rather as an accomplice. White accomplices who are successfully doing the work, have the obligation to inform their networks and communities that anti-racism is a priority for themselves, their work, and their organizations. Because they have power, they must educate themselves and their peers towards building collective understanding of anti-racism.

For generations, American society has favored the visual of leaders who embody white, heterosexual, cisgender male characteristics. This requires members of the BIPOC community to interact with white individuals in predominantly white spaces in order to gain power. The power structures within organizations often place responsibility for anti-racism work on BIPOC who are more junior in positional power. This set of circumstances can limit their ability to fully realize the vision set out for the anti-racism work and can often mute its success (which may lead to further marginalization within the institution).

In many circumstances, the anti-racism work is projected onto BIPOC colleagues, set up for failure, and does not relinquish any power from white leaders. To be clear, BIPOC should not be solely responsible for operationalizing equity and diversity.

During 2020, many white leaders of cultural organizations were publicly observed bargaining to find solutions that do not relinquish any power within their performative allyship. As a sector, we must take this as a warning to do better: Removing systems of power-hoarding, creating spaces of power-sharing, and empowering BIPOC leaders are crucial steps towards liberation within the arts and education sectors.

Robyne Walker Murphy confronts PWI's to ask themselves, "What is your liberation philosophy?"

\section{To learn more about these concepts, check out the conversations below:}

- Michael J. Bobbitt: Ending Racism Starts With White People Giving Up Power

- Adia Tamar Whitaker: Creating the Balance Between I And We

- Toya Lillard: Nuggets of Freedom

- Robyne Walker Murphy, Toya Lillard and Durell Cooper: What Are You Willing to Give Up?

○ Part 1

o Part 2

- Peter J. Kuo: How Truly Is It Just About You?

- Takiema Bunche Smith and Jody Drezner Alperin: Yes, Reimagine! (If Not During A Pandemic When Might We?)

- Christina Eskridge and ChelseaDee Harrison: Where Does Anti-Racism Live in Your Practice? 


\section{SECTION 2: BIPOC SEEKING REPARATIONS, AWARDED IN FULL}

As we examine the impact of power in our work and our organizations, we must also imagine the best possible way of redistribution. In these circumstances, the "how" is just as important as the "what." As a practitioner, we encourage you to think: What is the best way to meaningfully uplift the BIPOC community?

In this section, we will share perspectives on how to meaningfully uplift the BIPOC community within the arts and cultural education field, related to the following big ideas:

- Listening First

- Adopting an Abolitionist Mindset

- Creating Pathways to Reparations

Humans are always changing. This change is the connector between the past, present, and future. In our work understanding the anti-racist work of arts and cultural practitioners, we quickly understood that real change requires explicit anti-racist action (arts education curriculum, staffing, artistic programming, etc.) that is both representative of and draws connections between the past, present and future. This concept is known as the 360 Timeline. Proponents of the 360 Timeline believe that everything happens in multitudes: the past is used by the present to create opportunities for the future.

Common throughout the interviews were specific tactics and strategies to meaningfully uplift the BIPOC community in the arts and cultural education sector by understanding the past within the context of the present to shape the future. Some tactics are simple while others are more complex.

\section{Listening First}

Before taking action, listening is required. As individuals and organizations begin to imagine solutions to the challenges confronting their communities, we must listen to those who have been oppressed first. Too often, those taking action make assumptions about what is best for those most impacted, without engaging in the meaningful act of listening. This listening is made more successful with accountability. Without transparency to one's community, any effort towards dismantling racism becomes fraught with challenges. It is the role of a community to hold its leaders accountable for their actions on behalf of the community.

In this specific time - amidst the global COVID-19 pandemic and aided by the technology of the Digital Age - people around the globe are focused on white leaders in America, awaiting their next moves to address an international health crisis. Are these leaders listening or are they assuming? To what extent are the leaders being held accountable? And to whom?

This scenario is no different in the arts and cultural education field. Many prominent leaders in the field are white Americans; many practitioners have been waiting for these leaders to direct them towards a solution to the problems the field faces resulting from the pandemic. Are these the right people to be leading the field? Are our leaders listening? How are they being held accountable? 


\section{Adopt an Abolitionist Mindset}

The answers to the above questions might be hard and may be viewed as disruptive or revolutionary in specific contexts. However, the approach taken by our next generation of field leaders must be that of an abolitionist mindset. This term - popularized through the 2010's and more so in the year 2020 - is understood as the undoing of the cultural norms and mindsets that trap us within punitive habits and logics.

As societies move forward, individuals are constantly challenging their thinking, social constructs, and definitions of what it means to be doing this work. Similarly organizations work to challenge the societal structures which enabled their own formation. As we saw throughout 2020, many societies, individuals, and organizations reckoned with their problematic past - some by choice and others by circumstance.

Individuals and organizations must embrace the hard questions in order to upend the cultural norms and mindsets which perpetuate racism and oppressive systems. This can be as simple as reviewing a mission statement or as difficult as closing a long-standing institution. Regardless of the path, however, as an arts and cultural education field, we have to ask the hard questions of ourselves and our institutions in order to understand the harm that has been caused; only then can we move on the path towards healing.

A key component of the abolitionist mindset is radical love. The act of radical love can balance the harm previously caused and the pain which may be caused during change. As such, radical love is an essential component to addressing issues of inequity.

\section{Creating Pathways to Reparations}

Acknowledging harm is a necessary step in the path to anti-racism. With this acknowledgment, comes shared learning about how the harm was caused (along with the abolitionist mindset and radical love included in that process). Once better understood, one should begin down the path of reparations.

In a just America, individuals would be given appropriate financial resources to satisfy their basic needs to function in society - also known as cooperative economics. Since this is not the circumstance due to a long history of systemic racial oppression, the country must focus on a path of reparations which address the financial divide.

For BIPOC and BIPOC-led programs and organizations, the arts and cultural educator sector can enable diverse funding streams to support the infrastructure educating in and through the numerous BIPOC cultures within our country. Many ideas were shared in interviews, including:

- Receiving equal donor benefits across levels of giving

- Demanding foundations to change funding policies for eligibility

- Paying workers a fair wage, proportionally

- Diversifying boards

- Hiring BIPOC in senior management positions 
Financial reparations are one pathway; to honor the fullness of life, non-monetary reparations should also be implemented. As previously mentioned, PWIs dominate resources, including physical space. In many communities BIPOC spaces do not receive the same support as predominantly white spaces. Here are some ideas to construct equitable spaces:

- Increasing sense of belonging through integration methods in predominantly white spaces

- Changing PWI (Predominately White Institution) to PMI (Predominantly Multiracial Institution)

- Affirming the notion that it is also okay to be other than white

- Constructing braver environments for personal reflection, where individuals share their stories with others in order to secure a sense of liberated community

- Honoring Black Excellence; a term coined by Dr. Gholdy Muhammad that ultimately acts as a way to accentuates the beauty and complexity of Blackness and celebrate the positive significance the Black community has provided within society. Instead, automatically thinking about the negatives towards this community, shift the narrative to hone-in on the positives that this group brings to the table.

\section{To learn more about these concepts, check out the conversations below:}

- Khalia Davis: Conversations About Racism Are Not Just Ages 18+

- Adia Tamar Whitaker: Creating the Balance Between I And We

- Toya Lillard: Nuggets of Freedom

- C. Brian William: It's an Old Battle

- Carin Ford and Lisa Dawn Cave: Conversations of Change

- Idris Goodwin: WE CAN DO THIS! 


\section{SECTION 3: DECOLONIZING THE ARTS AND CULTURAL EDUCATION FIELD}

Why did it take so long? Why did someone have to die before people considered the value of humanity? These are some of the questions that we know the answers to avoid dialoguing about because they feel uncomfortable - often because we are complicit. As practitioners, we encourage you to think: What

\section{actions can I take?}

In this section, we will address how reflection should be manifested into action to help guide anti-racist practices in arts and cultural education, related to the following big ideas:

- Staying Attentive

- Creating Brave and Liberated Spaces

- Honoring Expertise

Common throughout the interviews was the conceptualization of liberation through arts and cultural education - and also the question: Do white people know what a racially liberated world looks like? It is clear that no amount of education from our white counterparts can instill this knowingness about the Black experience (or other IPOC) because it can never be their experience. When white people are prompted to explain their relationships with racism, often they deflect the question by referencing others who have committed racist acts. This action is unacceptable and can be combatted through the ongoing practice of decolonizing.

\section{Staying Attentive}

Even the most woke white individuals were thrusted into a wave of awakening that challenged their own progressive mindsets and held them responsible during the Summer of 2020. In the education sector, educators and systems were taking stock of their complicity in the oppression of Black and brown children. In the cultural sector, organizations began reckoning with racist policies, erasure of cultures, and inequitable practices.

How do we dismantle damaging behaviors? Well, it depends on the willingness to change. The false narrative, "everyone can change," has built an environment of complacency. As a society, we mustn't be complacent, but rather challenge ourselves and our institutions to constantly improve, remain vigilant, and hold each other accountable.

In the arts and cultural education sector this could include the following ongoing practices:

- Reviewing curriculum for colonized perspectives and singular histories

- Honoring diverse learning styles through multiple evaluation methods

- Offering many communications methods

- Depicting real-life scenarios aligned with the current student population

- Encouraging culturally specific artistic practices learned from family in the school or classroom

The practice of ongoing evaluation isn't out of the norm for educators or institutions; we must now apply it to our arts and cultural education practice - specifically the content - to ensure that it is and 14 remains decolonized. 


\section{Creating Braver and Liberated Spaces}

Those in power have a responsibility to relinquish their power and open space (traditionally white spaces) for those who want to make positive change even if it goes against the norm. Leadership requires individuals willing to listen before they act because a duty exists to provide braver and more liberated spaces where communities can authentically come together, because true collaboration requires comfortability.

In education and cultural organizations these spaces are often dominated by white, Eurocentric models, like theatres and lecture halls. How can organizations embrace BIPOC cultures to shape their physical spaces?

Similarly, communications styles employed dominantly through arts and cultural education work observe Western tradition. How can practitioners and organizations differentiate communications styles to liberate the meta-physical spaces we share?

\section{Honoring Expertise}

With arts organizations having the ability to inspire imagination, they can organically cultivate empathy, which then can be shared to surface truth in these spaces. Therefore, the sector's educational tools need to represent all identities, not just the white Eurocentric canon.

Acknowledging the harm this can cause through damaging narratives, it is the responsibility of arts and cultural (and educational) organizations to honor the expertise of their communities, and showcase that knowledge on stages, in galleries, and through their distribution channels. This act encourages greater participation by communities, celebrates the community's contributions, and enables great ownership of narratives.

Arts and cultural institutions have been notoriously bad about protecting the traditional, white, and Western canon of the arts. Now is not the time to cancel organizations, but rather hold them accountable. How can communities hold a mirror up to those organizations to reflect the exclusionary practices?

\section{To learn more about these large concepts, check out the conversations below:}

- Michael J. Bobbitt: Ending Racism Starts With White People Giving Up Power

- Quanice G. Floyd: Bringing You In The Space

- Toya Lillard: Nuggets Of Freedom

- Ashley Herring: It's Never Too Late To Be Radically Transformed

- Dr. Daphnie Sicre: You Know You Have The Power, Right?

- Robyne Walker Murphy, Toya Lillard and Durell Cooper: What Are You Willing To Give Up?

- Part 1

O Part 2

- Takiema Bunche Smith and Jody Drezner Alperin: Yes, Reimagine! (If Not During A Pandemic When Might We?)

- Alaina Newell: What Power Do We Actually Yield? (...Whether They Give It To Us Or Not)

- Dexter J. Singleton: Who's Your Leader?

- Christina Eskridge and ChelseaDee Harrison: Where Does Anti-Racism Live In Your Practice?

- Idris Goodwin: WE CAN DO THIS! 


\section{A CALL TO ACTION}

Privilege is not a bad thing; it just depends on how one uses it. If you feel that you have privilege, ask yourself: "What can I do with this privilege to support those who have been oppressed in the effort to construct a racially-just world?"

Cardozie Jones compares his work as an antiracism consultant to the work of a doula. He brings a natural expertise of liberation to show people that they, too, can do this work authentically. Once an individual makes the choice to authentically engage in fighting systems of oppression, they end up accompanying others to support the change as well.

This shared responsibility is how change will occur. Too often BIPOC are called upon to do this work for no compensation. White individuals must take on this work. BIPOC, remember, you have the power to rest and say no. This exhausting routine can break people down, even those who truly want to provide good into the world. Yet, when we work together, we can achieve great things.

Our society, specifically in the United States, has to embrace interdependence as a means of progress towards an anti-racist society. With a system that supports the construction of silos, realizing our interconnectedness can be the key to achieving a more just world

As arts and cultural practitioners, we must remove ourselves from our silos to see other perspectives and gain a broader view. That view enables us to expand our efforts in an effort to gain a collective understanding. The old adage holds true, "You only know what you know," but we cannot stay complacent in only knowing what we know. These essential moments in time push us to learn new things, maintain accountability, and build on the foundations of freedom.

\section{Ask yourself, if we can't go back, where do we go from here?}




\section{PROJECT ARCHIVE}

92 9 Episode 1 - The First Episode Of "We Can't Go Back" Is Live!

- Blog Post

- Video

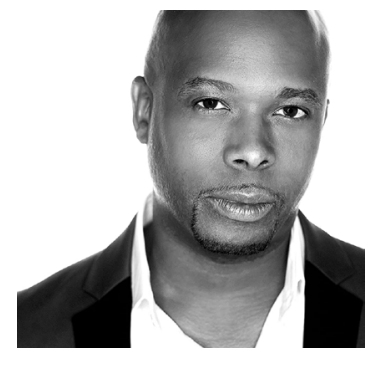

Episode 2 -The 2nd Episode Of "We Can't Go Back" Is Live! with Chesney Snow

- Blog Post

- Video

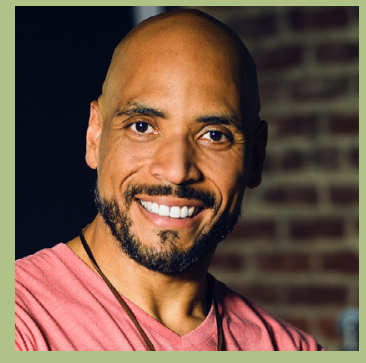

Episode 3 -Ending Racism Starts With White People Giving Up Power with Michael J. Bobbitt

- Blog Post

- Video

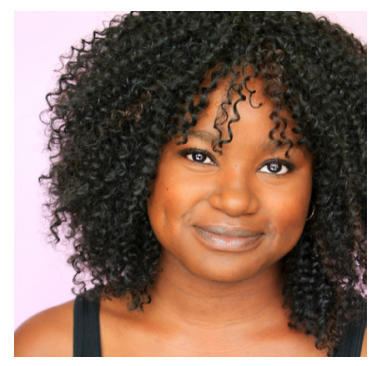

Episode 4 - Conversations About Racism Are Not Just Ages 18+ with Khalia Davis

- Blog Post

- Video

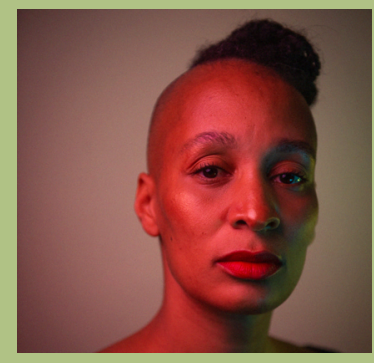

Episode 5 - Creating The Balance Between I And We with Adia Tamar Whitaker

- Blog Post

- Video

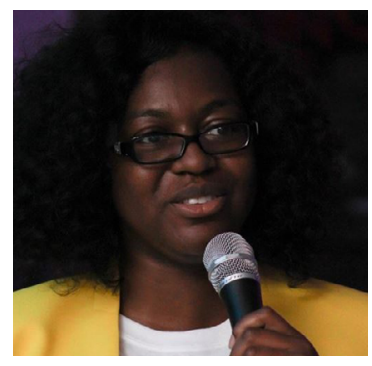

Episode 6 - Bringing You In The Space with Quanice G. Floyd

- Blog Post

- Video 
Episode 7 - Nuggets Of Freedom with Toya Lillard

- Blog Post

- $\underline{\text { Video }}$

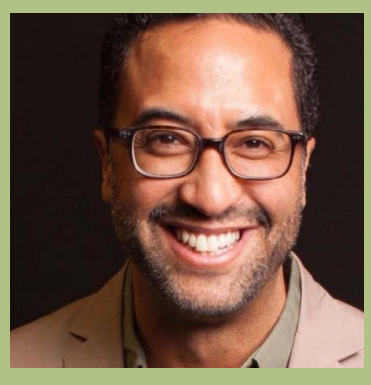

Episode 8 - It's An Old Battle with C. Brian William

- Blog Post

- $\underline{\text { Video }}$

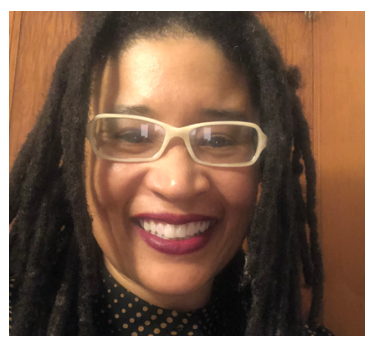

Episode 9 - It's Never Too Late To Be Radically Transformed with Ashley Herring

- Blog Post

- Video

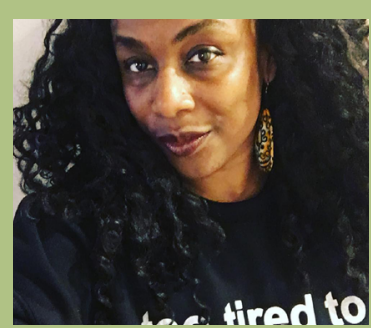

Episode 10 - What Are You Willing To Give Up? (Part 1) with Robyne Walker Murphy, Toya Lillard, and Durell Cooper

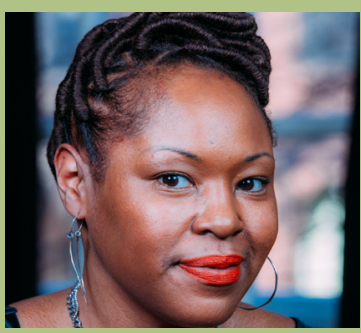

- Blog Post

- $\underline{\text { Video }}$

Episode 11 - What Are You Willing To Give Up? (Part 2) with Robyne Walker Murphy, Toya Lillard, and Durell Cooper

- Blog Post

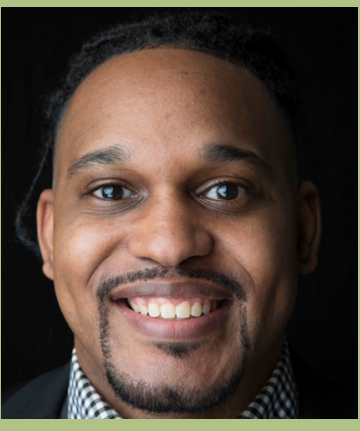

- $\underline{\text { Video }}$ 


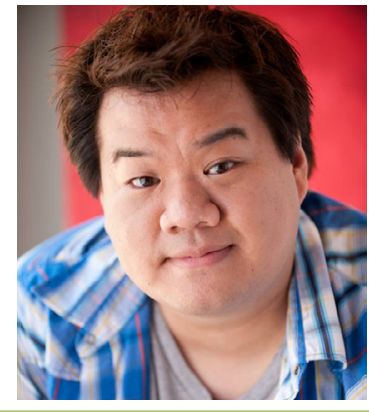

Episode 12 - How Truly Is It Just About You? with Peter J. Kuo

- Blog Post

- Video

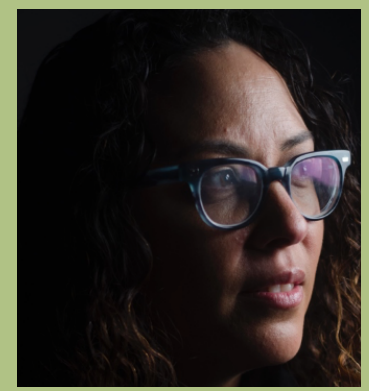

Episode 13 - You Know You Have The Power, Right? with Dr. Daphnie Sicre

- Blog Post

- Video

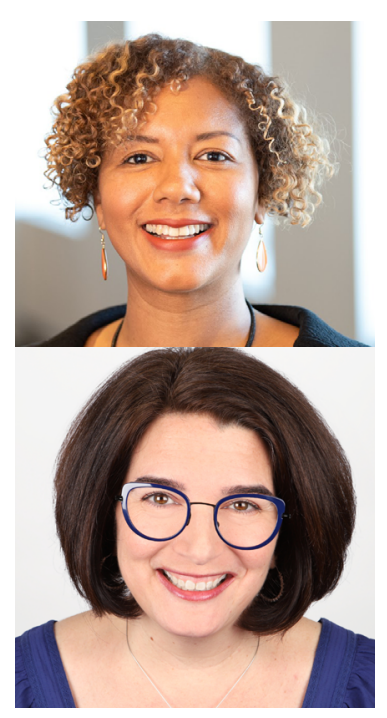

Episode 14 - Yes, Reimagine! (If Not During A Pandemic When Might We?) with Takiema Bunche Smith and Jody Drezner Alperin

- Blog Post

- Video

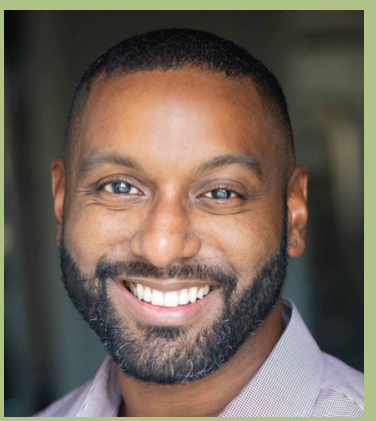

Episode 15 - Revolution Is Not Risk-Free with Cardozie Jones

- Blog Post

- Video

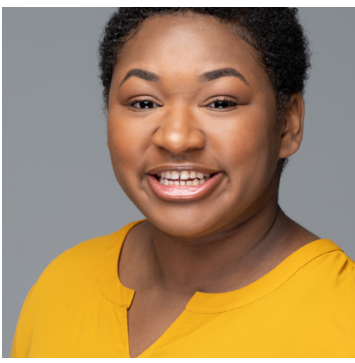

Episode 16 - What Power Do We Actually Yield? (...Whether They Give It To Us Or Not) with Alaina Newell

- Blog Post

- Video 
Episode 17 - Who's Your Leader? with Dexter J. Singleton

- Blog Post

- Video

Episode 18 - Conversations Of Change with Carin Ford and Lisa Dawn Cave

- Blog Post

- Video

Episode 19 - Where Does Anti-Racism Live In Your Practice? with Christina Eskridge and ChelseaDee Harrison

- Blog Post

- Video

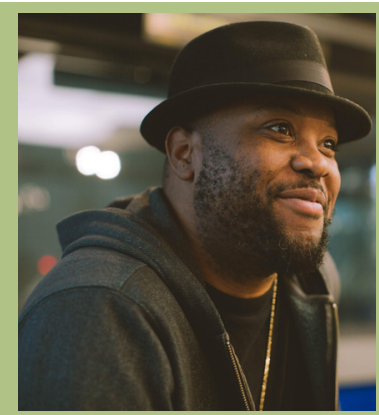

Episode 20 - WE CAN DO THIS! with Idris Goodwin

- Blog Post

- Video 


\section{RECOMMENDED RESOURCES}

A collection of websites, publications, toolkits, etc. mentioned throughout "We Can't Go Back"

\section{Concepts}

- Stono Rebellion 1739 - The Stono Rebellion was a slave rebellion that began on 9 September 1739, in the colony of South Carolina. It was the largest slave uprising in the British mainland colonies, with 25 colonists and 35 to 50 Africans killed.

- The Negro Act of 1740 - On May 10, 1740, the South Carolina Assembly enacted the "Bill for the better ordering and governing of Negroes and other slaves in this province," also known as the Negro Act of 1740. The Negro Act rendered enslaved Africans human chattel and revoked all forms of civil rights.

- Education Industrial Complex - Non-profit industrial complex, or "NPIC" for short, is a term which is used by social justice activists to describe the way non-profit organizations, governments, and businesses are related. Many activists carry out their work as employees of or with the assistance of non-profit organizations.

- Non-Profit Industrial Complex - In 2004, along with women of color at UC Santa Barbara, INCITE! organized the conference: "The Revolution Will Not Be Funded: Beyond The Non-Profit Industrial Complex." This conference drew in hundreds of organizers and activists searching for a space to address the ways in which the non-profit/NGO structure often obstructs radical movement building.

- Braver spaces - The intent is to encourage and empower all who enter this space to enact personal bravery; to express oneself authentically while participating in a way that protects and strengthens boundaries. Our hope is that by holding space together while adhering to the following common goals, we can create a safe container that enables all of us to embody our values while cultivating a clearer vision for the world we wish to live in. We are committed to accountability and growth through self-reflection. These are the values we strive to uphold, and the ones we think best support our mission of consent, respect, and inclusion.

- Futurist - Thinking about the future allows us to imagine what kind of future we want to live in and how we can get there.

- The 1619 Project Curriculum - This is full of resources that challenges the narrative of slavery with reading guides, activities, and tons of other resources. While designed for classroom use, it is incredibly detailed and in-depth with historical information. 


\section{People \& Organizations}

This specific list contains the organizations that our interviewees worked at

- Ailey School

- Anahsa Consulting Firm

- Arts Education in Maryland Schools Alliance

- Áse Dance Theatre Collective

- Bay Area Children's Theater

- Black Theater United

- Blackyard

- College of Colorado's Fine Arts Department

- Colorado College - Department of Theater and Dance

- Cultural Innovation Group

- The Fourth Wall

- Dr. Gholdy Muhammad

- Groundswell

- Linda Villarosa

- Loyola Marymount University - The College of Communication \& Fine Arts

- New Repertory Theatre

- New Victory Theater

- Step Afrika

- True North EDI

- viBe Theater Experience

- Western Carolina University 


\section{Websites}

This list contains websites and resources mentioned by interviewees:

- 2020 Diversity Forum hosted by University of Pittsburgh - This was hosted this week; the

Full Programs with Session Links leads to all the available recorded content and applies to higher education, community, and public institutions

- Workplace Racial Equity Symposium hosted by Denver Public Library - This was an event that took place a few weeks ago and while mostly centers around libraries, the speakers are various types of community organizers and professionals. If you go to "Replays" at the top, you should be able to access all the recorded content.

- 2020 Intro to Racism and White Privilege Webinar Course hosted by People's School of DC

- This is an ongoing free 24 anti-racism class that are recorded and emailed as they are released. Some upcoming sessions may offer a live viewing component as well.

- Disrupting Whiteness in Libraries and Librarianship: A Reading List developed by University of Wisconsin-Madison, the Office of the Gender and Women's Studies Librarian - This is a super long reading list that primarily applies to libraries but can be considered in all cultural and public institutions.

- Tools for Anti-Racist Teaching by PBS Teachers Lounge - I have not personally gone through this one in detail, but I have been looking to identify resources for individuals working with youth. It is a four-part series for educators focused on media literacy.

- African American History: From Emancipation to the Present through Open Yale Course This is a recorded, downloadable course from Yale University that examines the African American experience in U.S. history. As a note, this course was developed and recorded in Spring 2010.

- Making Sense of the Moment: The Library's Role in Helping Us Understand Race and Racism - This conversation is led by the State Library of Ohio and is open to anyone.

- Anti-Racism Resource Collection - Anti-racism work is an ongoing, everyday process of active allyship, listening and learning. In that spirit, the Resource Sharing Project provides a round-up of some of our favorite resources to aid in your journey to undo racism in your coalition and community. Anti-racism work is an integral part of our work to end sexual violence and essential to advance women of color leadership in our movement and beyond.

- Multicultural Education Pavilion

- Inclusiveness Index - The Inclusiveness Index Report is an annual publication that identifies and captures the degree of group-based inclusion and marginality experienced across the world and within the United States. 
- Opportunities for White People in the Fight for Racial Justice - The ideas captured on this website, very much a work in progress, have been developed to support White people to act for racial justice. It draws from ideas and resources developed mostly by Black, Brown and People of Color, and has been edited by Black, Brown, and People of Color. I recognize that categorizing actions under the labels of Actor, Ally, and Accomplice is an oversimplification, but hopefully this chart challenges all of us White folks to go outside of our comfort zones, take some bigger risks, and make some more significant sacrifices because this is what we've been asked to do by those most impacted by racism, colonialism, patriarchy, white supremacy, xenophobia, and hyper-capitalism. I believe that for real change to occur, we must confront and challenge all people, policies, systems, etc., that maintain privileges and power for White people.

- FREE PLAY: Open-Source Scripts Toward an Antiracist Tomorrow - Award-winning playwright, poet, and changemaker Idris Goodwin offers five short plays for multigenerational audiences to spark conversation about race in America.

- The Guide To Getting What's Yours - Part poetry, part portraiture, part dance, and part music- the play takes an irreverent and impassioned look at the ways we create our identity. The play asks: How was I created and who's really in control of who I am? The Guide is inspired by the life (and crimes) of the infamous, international jewel thief, Doris Payne, who travelled the world successfully pulling off movie-worthy heists during a time when most African Americans were fighting for basic human rights in the country they built. How does someone envision a future for himself or herself that goes far beyond the mediocre standards forced upon them?

- CreativeMornings Presentation - Robyne Walker Murphy: Social Justice is Rooted in Love

- \#BlackLivesMatter in TYA: ALL AMERICAN BOYS as a resource for Young People \& Families - TYA/USA believes that theater can play an important role in helping young people and families explore personal narratives to face hard truths and inspire meaningful change. Last year, TYA/USA kicked off the 2019 Festival \& Conference with a reading of a powerful new work that urgently speaks to our current moment. Today, we are making it available to you and your communities as a resource.

- The Freedom and Fulfillment of Home-Schooling - Nine families shared with us why they chose to educate their children outside the traditional school system.

- AKPLAY Materials for Producing Partners - Use this Active Audience Guide as a resource with tools for your classroom to engage on the topic of racism. Curated by some of the field's top education professionals, this guide has: Activities geared towards every age group, How to take action, List of resources for adults to start conversations with their kids about racism, ideas for your own curriculum surrounding the topic of racism and so much more!

- Here to Help: Community Resources - The deaths of George Floyd, Breonna Taylor and Ahmaud Arbery and subsequent protests in Pittsburgh and across the country have been triggering and traumatic events for our community. Carnegie Library of Pittsburgh is a reliable source for information and resources to help understand and process these events. 
- Always Available on Hoopla: Race and Healing - Whether we are engaging in social activism and working for social justice for the first time or as a regular practice, we must be prepared for ongoing growth and learning. As something that is often characterized as a "fight," This work can (necessarily) cause trauma and stress. After all, it involves learning about historical trauma and/or having to educate or inform others about personal and historical trauma.

- Talking About Race With Kids and Teens - Talking with children, preschoolers, teens or in between, about current events can be challenging in the best of times. When illness, inequity, violence and hate surround us, it can be an overwhelming prospect.

- Woke Kindergarten - a global, abolitionist early learning community, creative expanse and consultancy supporting children, families, educators and organizations in their commitment to abolitionist early education and pro-Black liberation.

- American Theatre: Boards Are Broken, So Let's Break and Remake Them by Michael J. Bobbitt - Nonprofit theatre boards are unrepresentative, out of touch, and more often oppressive than supportive. We can and must do this better.

- American Theatre: Let's Be Real: These Programs Won't End Racism at Your Theatre by Michael J. Bobbitt - Ending white supremacy at your institution requires an organization-wide commitment to change in both culture and policy. 


\section{Videos}

This list contains videos referenced by interviewees:

- The Difference Between Being "Not Racist" and Antiracist - There is no such thing as being "not racist," says author and historian Ibram X. Kendi. In this vital conversation, he defines the transformative concept of antiracism to help us more clearly recognize, take responsibility for and reject prejudices in our public policies, workplaces and personal beliefs. Learn how you can actively use this awareness to uproot injustice and inequality in the world - - and replace it with love. (This virtual interview, hosted by TED's current affairs curator Whitney Pennington Rodgers and speaker development curator Cloe Shasha, was recorded June 9, 2020.)

- The Path Ending Systemic Racism in the U.S. - In a time of mourning and anger over the ongoing violence inflicted on Black communities by police in the US and the lack of accountability from national leadership, what is the path forward? Sharing urgent insights into this historic moment, Dr. Phillip Atiba Goff, Rashad Robinson, Dr. Bernice King and Anthony D. Romero discuss dismantling the systems of oppression and racism responsible for tragedies like the murders of Ahmaud Arbery, Breonna Taylor, George Floyd and far too many others - - and explore how the US can start to live up to its ideals. (This discussion, hosted by head of TED Chris Anderson and current affairs curator Whitney Pennington Rodgers, was recorded on June 3, 2020.)

- We Need to Talk About an Injustice - In an engaging and personal talk - - with cameo appearances from his grandmother and Rosa Parks - - human rights lawyer Bryan Stevenson shares some hard truths about America's justice system, starting with a massive imbalance along racial lines: a third of the country's black male population has been incarcerated at some point in their lives. These issues, which are wrapped up in America's unexamined history, are rarely talked about with this level of candor, insight and persuasiveness.

- Elevate Theatre Company - YouTube channel

- HOLA Talks Online: Teaching Theater online during COVID-19 by Daphnie Sicre

- TEACHING THEATRE ONLINE - NYTW Director of Education Alexander Santiago-Jirau moderates a conversation with Heleya de Barros, Sobha Kavanakudiyil, Michael Rohd and Dr. Daphnie Sicre on how artists and educators can adapt their practice to teach the art form online. Join us for some practical tips, ideas and resources.

- 60 Second Lectures 2019: Daphnie Sicre

- The Play 14 Trailer - The play 14 is about the aftermath of 20 Mexican immigrants trying to cross the border near Yuma, AZ, 14 died from dehydration!

- In The Heights by LMU - In the spring semester of 2020, Loyola Marymount University put up their rendition of the award-winning musical: In The Heights. This is a mini documentary that shows their journey from rehearsal to stage, and how this story in particular has touched them. 
- Live Video Theatre - We produced IN LOVE AND WARCRAFT this spring as part of our MFA season, as a re-envisioned online production in reaction to Covid-19. It's back as part of our mainstage 20/21/22 season, available to watch through Sep 25. Want a sneak peek? Here are three behind-the-camera perspectives from director Peter J. Kuo, stage manager Ariana Johnson, and sound designer Lana Palmer on how they pivoted from onstage to onscreen.

- Blog Post by Peter J. Kuo - On, June 3rd, at an online theatre conference, a prompt was given to the tune of, "What can we learn from Covid-19 to reopen our theatres, with an attention and focus to dismantling White supremacy and anti-Blackness?"

- Flow Web Series - Episode 1 - Documentary filmmaker and cultural strategist Durell Cooper takes a critical look at power dynamics from the perspectives of people of color across multiple industries. In this groundbreaking docuseries he explores the struggles and triumphs of black and brown bodies within the arts, culture, education, philanthropy, science, finance, and fashion industries. In this pilot episode, he visits world renowned marketing strategist and author Donna Walker-Khune in Newark, New Jersey. These films are produced by Emmy Award winner Haigi Suka and executive produced by Cultural Innovation Group, LLC.

\section{Books}

- On Being Included: Racism and Diversity in Institutional Life by Sara Ahmed

- Better Allies: Everyday Actions to Create Inclusive, Engaging Workplaces by Karen Catlin

- Biased: Uncovering the Hidden Prejudice that Shapes What We See, Think, and Do by Jennifer L. Eberhardt

- Some of My Best Friends are Black: The Strange Story of Integration in America by Tanner Colby

- Just Mercy: A Story of Justice and Redemption by Bryan Stevenson

- A Kids Book about Racism by Jelani Memory 


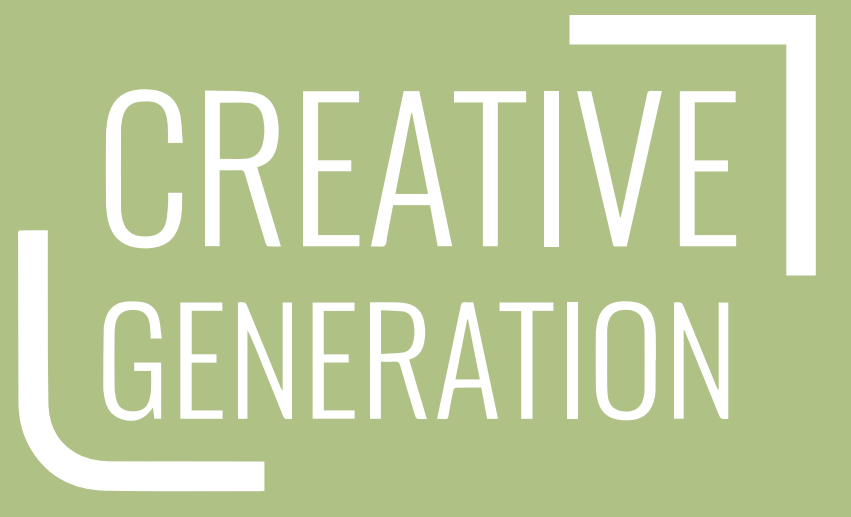

www.Creative-Generation.org
in $y \mathbf{f}$ o? @Campaign4Genc 